\title{
Generation of Neural Progenitor Cells from Pig Embryonic Germ Cells
}

\author{
Kwang-Hwan Choi ${ }^{1}$, Dong-Kyung Lee ${ }^{1}$, Jong-Nam Oh ${ }^{1}$, Seung-Hun Kim ${ }^{1}$, Mingyun Lee ${ }^{1}$, \\ Jinsol Jeong ${ }^{1}$, Gyung Cheol Choe ${ }^{1}$ and Chang-Kyu Lee ${ }^{1,2, *}$ \\ ${ }^{1}$ Department of Agricultural Biotechnology, Animal Biotechnology Major, and Research Institute of Agriculture and Life \\ Science, Seoul National University, Seoul 08826, Korea \\ ${ }^{2}$ Institute of Green Bio Science and Technology, Seoul National University, Pyeongchang 25354, Korea
}

Received March 3, 2020

Revised March 17, 2020

Accepted March 17, 2020

*Correspondence

Chang-Kyu Lee

E-mail: leeck@snu.ac.kr

ORCID

https://orcid.org/0000-0001-6341-0013

\begin{abstract}
As a preclinical study, many researchers have been attempted to convert the porcine PSCs into several differentiated cells with transplantation of the differentiated cells into the pigs. Here, we attempted to derive neuronal progenitor cells from pig embryonic germ cells (EGCs). As a result, neuronal progenitor cells could be derived directly from pig embryonic germ cells through the serum-free floating culture of EB-like aggregates (SFEB) method. Treating retinoic acid was more efficient for inducing neuronal lineages from EGCs rather than inhibiting SMAD signaling. The differentiated cells expressed neuronal markers such as PAX6, NESTIN, and SOX1 as determined by qRT-PCR and immunostaining. These data indicated that pig EGCs could provide valid models for human therapy. Finally, it is suggested that developing transgenic pig for disease models as well as differentiation methods will provide basic preclinical data for human regenerative medicine and lead to the success of stem cell therapy.
\end{abstract}

Keywords: embryonic germ cells, neuronal differentiation, pig, retinoic acid

\section{INTRODUCTION}

In 1998, the establishment of human embryonic stem cells (ESCs) paved the way for regenerative medicine by tissue engineering. This trend was accelerated by the establishment of human induced pluripotent stem cells (iPSCs) and cloned ESCs in 2007 and 2013, respectively (Choi and Lee, 2019). Accompanied by the generation of human PSCs, methods for differentiation into various types of cells have been developed (reviewed in (Tabar and Studer, 2014)). Recently, in addition to differentiation into specific cell types, putative organs composed of multi-cellular tissues, named organoid, were generated in vitro (reviewed in (Yin et al., 2016)). Various types of tissues including intestinal, brain, eye and kidney have been researched. Because they more closely resemble in vivo-organs and tissues than a single type of cells, these organoids might provide in vitro-tools for drug screening, disease modeling, and organ development models. As a clinical trial of human PSCs for cell therapy as mentioned above, it makes the research of animal PSCs involving differentiation and transplantation study more important as a preliminary.

For this reason, many researchers have been attempted to convert the porcine PSCs into various types of somatic cells with transplantation of the differentiated cells into the pigs. First of all, hepatocytes have been derived from pig iPSCs and ESCs (Ao et al., 2014; Park et al., 2015). The 
differentiated cells from iPSCs and ESCs have molecular and functional similarities with hepatocytes. They have abilities including lipid metabolism, glycogen storage, and LDL uptake. Moreover, several studies have tried to transplant iPSCs or differentiated cells into pig disease models. Rod photoreceptors and retinal pigment epithelial cells were produced from pig iPSCs, and then these cells were transplanted into subretinal space of pigs (Zhou et al., 2011; Sohn et al., 2015). Other groups used undifferentiated pig iPSCs to treat myocardial infarction and myocardial ischemia (Li et al., 2013; Zhang et al., 2014). The engrafted iPSCs ameliorated symptoms via differentiation into vessel cells (Li et al., 2013). However, undifferentiated PSCs have the potential to form tumors when engrafted into the body (Lee et al., 2013), it needs to be careful about the implant of undifferentiation PSCs. Recent studies showed that PGCs and skeletal myotubes could be induced from pig iPSCs (Wang et al., 2016; Genovese et al., 2017).

Neuron cells derived from PSCs such as dopaminergic neuron and retinal cells have been considered as alternative cell sources for treating neuronal diseases (Osakada et al., 2008). In the pig, neuronal cells have successfully derived from pig PSCs (Puy et al., 2010; Gallegos-Cárdenas et al., 2015). Here, we attempted to derive neuronal progenitor cells using previously derived pig embryonic germ cells (EGCs) (Choi et al., 2018). To optimize the culture conditions for inducing neuronal cells, various signaling molecules involved in neuronal development were analyzed. As a result, retinoic acid treatment, rather than inhibition of SMAD signaling, have more crucial roles in neural differentiation of pEGCs. Similar to other species, neuronal progenitor cells induced by treatment of retinoic acid expressed markers of neuronal progenitor such as PAX6, NESTIN and SOX1 as determined by immunostaining and PCR analysis.

\section{MATERIALS AND METHODS}

\section{Animal care}

The care and experimental use of pigs and mice were approved by the Institutional Animal Care and Use Committees (IACUC) at Seoul National University (Approval No.: SNU-16120-9-1 for MEFs isolation). Pregnant ICR mice were purchased from SAMTACO BIO Inc., Korea. The mice were taken care according to the standard protocol of IACUC and sacrificed by cervical dislocation after anesthesia.

\section{Culture of pig embryonic germ cells}

Pig embryonic germ cells (EGCs) previously derived were used in this study (Choi et al., 2018). According to the previous study, the EGCs were cultured with EGC media supplemented with $40 \mathrm{ng} / \mathrm{mL}$ human recombinant basic fibroblast growth factor (bFGF; R\&D Systems). EGC media consisted of 1:1 mixture of Dulbecco's modified Eagle's medium (DMEM, low glucose) and Ham's F10 media containing $15 \%$ fetal bovine serum (FBS; collected and processed in the USA), $2 \mathrm{mM}$ glutamax, $0.1 \mathrm{mM}$ $\beta$-mercaptoethanol, $1 \times$ MEM nonessential amino acids, and $1 \times$ antibiotic-antimycotic (all from Gibco, USA). Subculture was performed every 7 days. EGC colonies were dissociated by treating $0.25 \%$ trypsin solution for 5 min and then transferred into new feeder cells. Media were changed every $24 \mathrm{~h}$ and all cells were cultured under humidified conditions containing $5 \% \mathrm{CO} 2$ at $37^{\circ} \mathrm{C}$.

\section{In vitro differentiation into neural progenitor cells}

Differentiation of neural lineage was accomplished according to the serum-free floating culture of EB-like aggregates (SFEB) methods with some modifications (Watanabe et al., 2005). Cultured EGCs were dissociated into single cells using $0.25 \%$ trypsin/EDTA solution (Welgene) and cultured in Ultra-Low attachment plates (Sigma Aldrich, MO, USA) with STEMdiff ${ }^{\mathrm{TM}}$ Neural Induction Medium (STEMCELL, Vancouver, Canada) containing $5 \mu \mathrm{M}$ retinoic acid (RA) and SMAD signaling inhibitors (SMADi; $400 \mu \mathrm{M}$ Noggin and $2 \mu \mathrm{M}$ SB431542) for 5 days. After suspension culture, the dissociated cells were aggregated and formed embryoid bodies. Cultured embryoid bodies were seeded on BD Matrigel ${ }^{\mathrm{TM}}$ (BD Biosciences, NJ, USA)coated plates and cultured for 8-11 days with STEMdiff ${ }^{\mathrm{TM}}$ Neural Induction Medium containing $10 \mathrm{ng} / \mathrm{mL}$ bFGF, RA, and SMAD inhibitors. After 8-11 days, differentiated cells were used for immunostaining or qPCR analysis.

\section{Quantitative real-time polymerase chain reaction (qPCR)}

Total RNA from individual samples was extracted using TRIzol $^{\oplus}$ reagent (Invitrogen, MA, USA) according to the manufacturer's instructions. Complementary DNA was synthesized using a High-capacity RNA-to-cDNA Kit (Applied Biosystems, CA, USA) according to the manufac- 
turer's instructions, producing a final volume of $20 \mu \mathrm{L}$. Extracted cDNA samples were amplified with DyNAmo HS SYBR Green qPCR Kit (Thermo Scientific, MA, USA) containing 1 pmol of each primer set listed in Table 1 in a $10 \mu \mathrm{L}$ reaction volume. Amplification and detection were conducted using the ABI 7300 Real-Time PCR system (Applied Biosystems) under the following conditions: one $\mathrm{cy}^{-}$ cle of $50^{\circ} \mathrm{C}$ for $2 \mathrm{~min}$ and $95^{\circ} \mathrm{C}$ for $10 \mathrm{~min}$, followed by 40 cycles of denaturation at $95^{\circ} \mathrm{C}$ for $15 \mathrm{sec}$ and annealing/ extension for $1 \mathrm{~min}$ (annealing/extension temperatures depended on each primer set). We analyzed the dissociation curve and loaded the amplified products on gels to confirm the specificity of PCR products. The relative expression level was calculated by normalizing the threshold cycle $(\mathrm{Ct})$ values of each gene to that of the ACTB via the $\Delta^{\text {-Ct }}$ method (Livak and Schmittgen, 2001).

\section{Immunostaining}

Differentiated cell samples were preincubated for 10 min at $4^{\circ} \mathrm{C}$ and fixed with $4 \%$ paraformaldehyde for 30 min. After washing twice with Dulbecco's phosphatebuffered saline (DPBS; Welgene), samples were treated for $1 \mathrm{~h}$ with $10 \%$ goat serum in DPBS to prevent nonspecific binding. Serum-treated cells were incubated overnight at $4^{\circ} \mathrm{C}$ with primary antibodies. The primary antibodies used were as follows: SOX1 (Santa Cruz Biotechnology, CA, USA; 1:50), PAX6 (Santa Cruz Biotechnology; 1:50), NESTIN (Santa Cruz Biotechnology; 1:50), and ZO-1 (Santa Cruz Biotechnology; 1:50). When used the antibodies for intracellular proteins such as SOX1 and PAX6, fixed cells were treated for 5 min with $0.2 \%$ Triton-X100 (SigmaAldrich, MO, USA) before serum blocking. After incubation with the primary antibody, the cells were treated for

Table 1. Primer sets for neuronal markers

\begin{tabular}{llc}
\hline Genes & \multicolumn{1}{c}{ Primer sequence } & Size \\
\hline \multirow{2}{*}{ PAX6 } & 5'- AGAGAAGACAGGCCAGCAAC -3' & 169 \\
& 5'- GGCAGAGCACTGTAGGTGTT -3' & \\
Nestin & 5'- TGCCTGGGGGAGGAATCTTTT -3' & 252 \\
& 5'- CTCTTCAGCCAGGTTGTCGC -3' & \\
PLAG1 & 5'- CAGCCAAGATTGGCCACAATG -3' & 116 \\
& 5'-AGCCATGTGCCTGATGACAGA -3' & \\
DACH1 & 5'- CAGGCTTTCGACCTGTTCCT -3' & 126 \\
& 5'- CAGTCCCCTCAAGATGCGAA -3' & \\
ACTB & 5'- GTGGACATCAGGAAGGACCTCTA -3' & 131 \\
& 5'-ATGATCTTGATCTTCATGGTGCT -3' & \\
\hline
\end{tabular}

$3 \mathrm{~h}$ at room temperature with Alexa Fluor-conjugated secondary antibodies. Nuclei were stained with Hoechst 33342 (Molecular Probes). Images of stained cells were captured using an inverted fluorescence microscope.

\section{Statistical analysis}

All gene expression data from qPCR analyses were statistically analyzed using GraphPad Prism 6 statistical software (GraphPad Software, CA, USA). Statistical differences between datasets were determined by one-way analyses of variance (ANOVAs) followed by Fisher's least significant difference (LSD) tests. Differences were considered significant at $p<0.05$.

\section{RESULTS}

\section{Pig EGCs can be differentiated into neural lineage by treating retinoic acid}

To apply pig PSCs for a therapeutic model, a development of methods for directed differentiation into specific lineages are important. For this reason, this study aimed to develop a method for inducing neural lineage from pig EGCs. It has been verified that several signaling including SMAD inhibition and retinoic acid are involved in differentiation into neural cells from pluripotent cells (Parsons et al., 2011). So, firstly, to find which molecules are most efficient in inducing neural cells from pig EGCs, SMAD signaling inhibitors and retinoic acid were analyzed (Fig. 1A). Embryoid bodies were successfully formed by suspension culture as presented in Fig. 1B and, after plating onto matrigel, they were cultured for 8 days (Fig. 1C). As measured by qPCR, neural-specific marker genes such as PAXG, NES, PLAG1, and DACH1 were highly expressed in the retinoic acid-treated group compared with other groups (Fig. 1D). When examined with various concentrations of retinoic acid (Fig. 2A and B), the expression of neural markers was most efficiently up-regulated in $5 \mu \mathrm{M}$ treated groups (Fig. 2C). Five $\mu \mathrm{M}$ retinoic acid successfully induced neural lineage-related genes during suspension culture (Fig. 2D). Furthermore, bFGF treatment during adherent culture facilitated the proliferation of neural progenitor cells (Fig. 3). Induced neural progenitor cells expressed neural markers such as SOX1, PAX6, ZO1, and NESTIN as determined by immunostaining (Fig. 4). Taken together, we developed methods for inducing neural lineage from pig EGC by treating retinoic acid. 
A

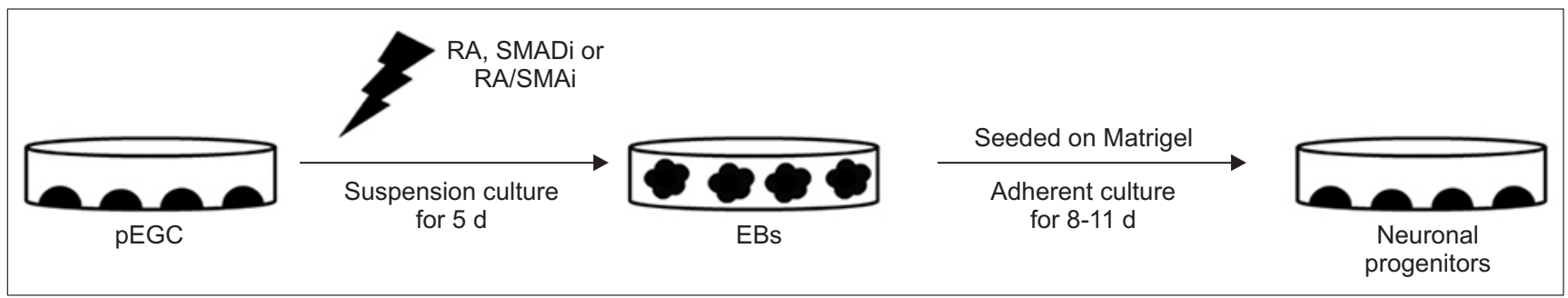

B
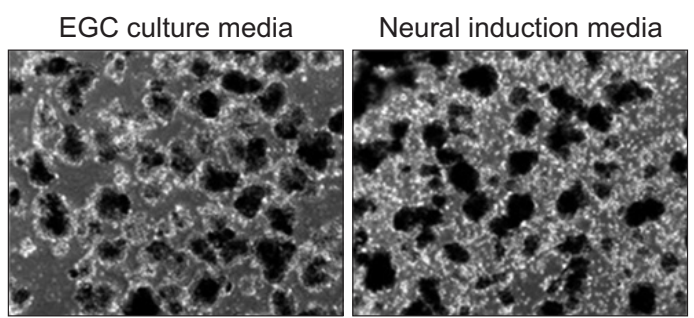

SMADi

RA

SMADi/RA

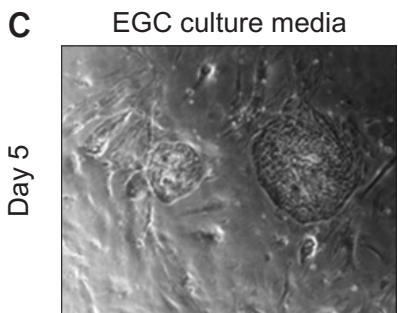

Neural induction media
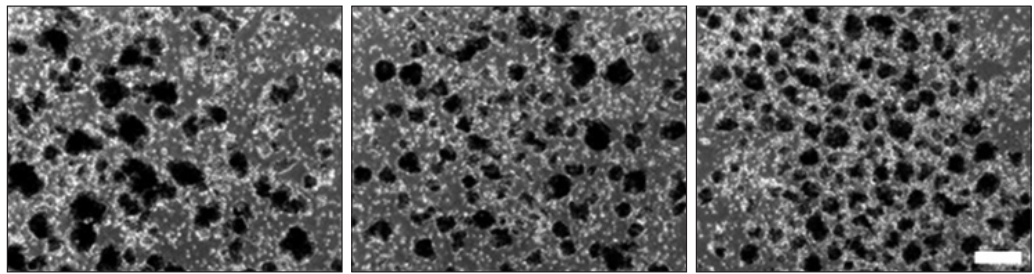

RA

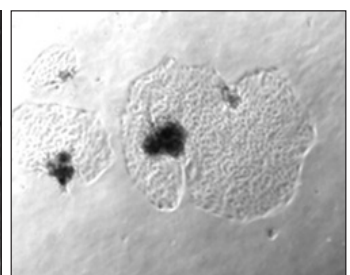

SMADi
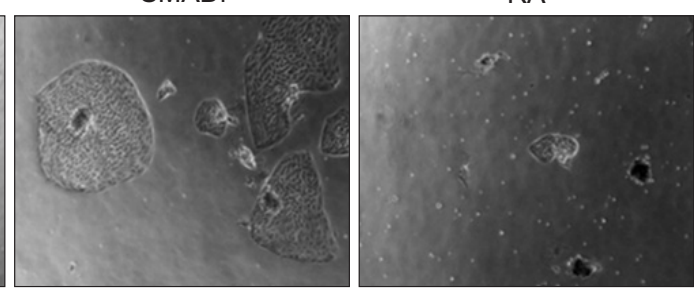

SMADi/RA
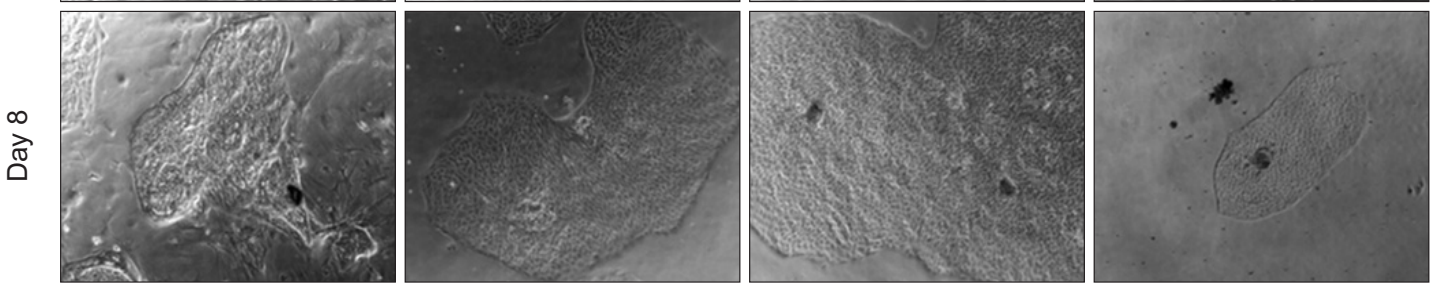

D PAX6

NESTIN
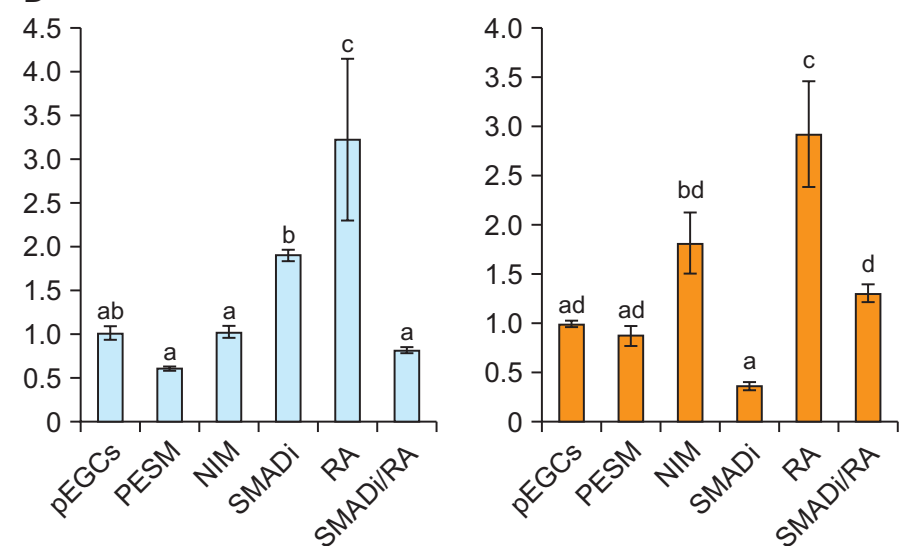

PLAG1
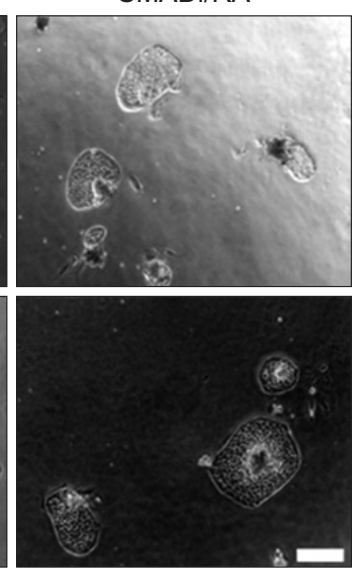

$\mathrm{DACH} 1$
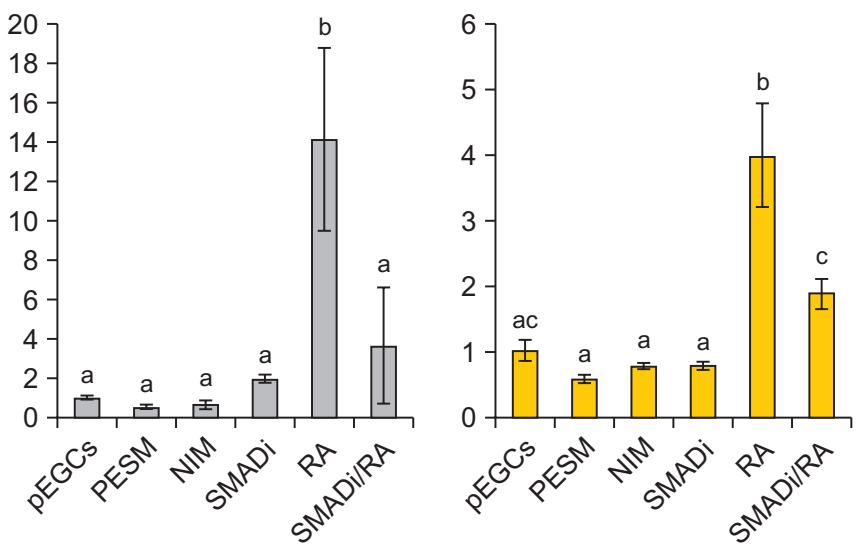

Fig. 1. Effects of culture conditions on neural differentiation in pig EGCs. (A) Differentiation of neural lineage was accomplished according to the serum-free floating culture of EB-like aggregates (SFEB) methods with some modifications. Differentiation was conducted with the porcine embryonic stem cell media (PESM) as a control media and the neural induction media (NIM). To find which molecules are most efficient in inducing neural cells from pig EGCs, SMAD signaling inhibitors and retinoic acid were selected. (B) Embryoid bodies were formed by suspension culture. (C) After plating onto matrigel, they were cultured for 8 days. (D) As measured by GPCR, genes expressed in neural progenitors were highly expressed in the retinoic acid-treated group compared with other groups. Scale bar $=400 \mu \mathrm{m}$. 

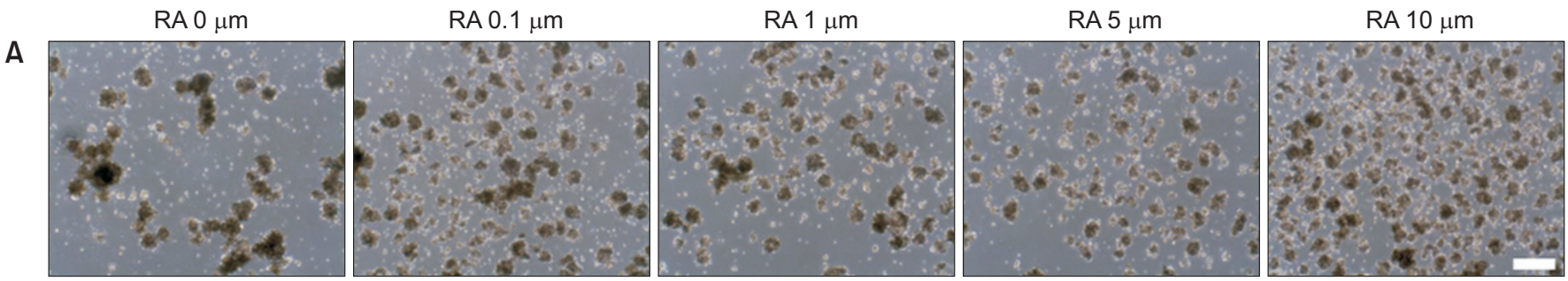

B

$\mathrm{RA} 0 \mu \mathrm{m}$

RA $0.1 \mu \mathrm{m}$

$\mathrm{RA} 1 \mu \mathrm{m}$

RA $5 \mu \mathrm{m}$

$\mathrm{RA} 10 \mu \mathrm{m}$
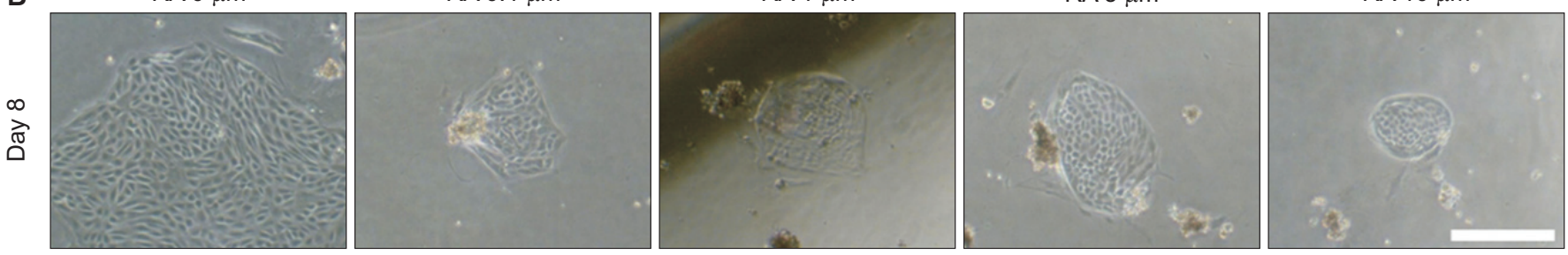

C

PAX6

NESTIN
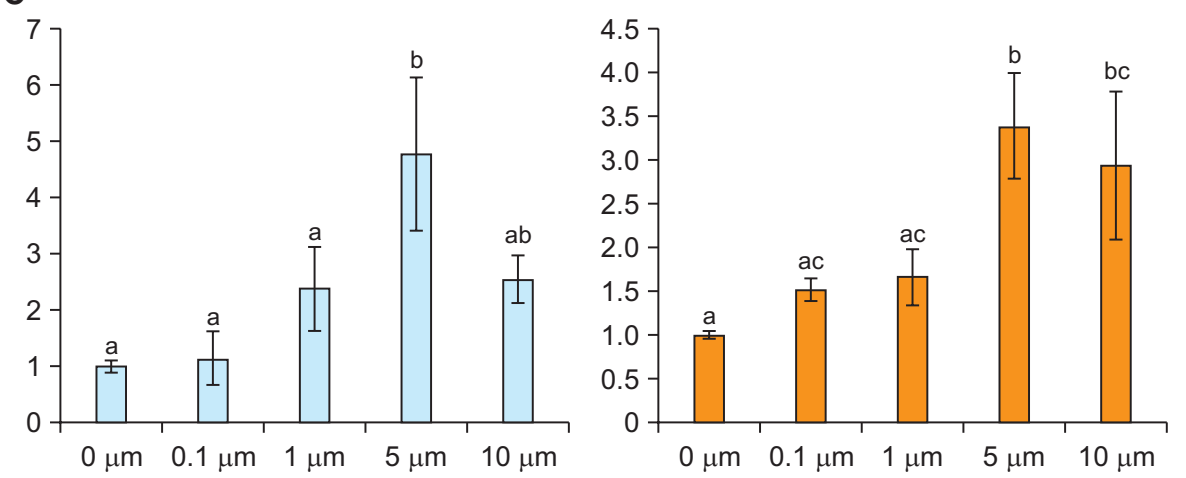

NESTIN
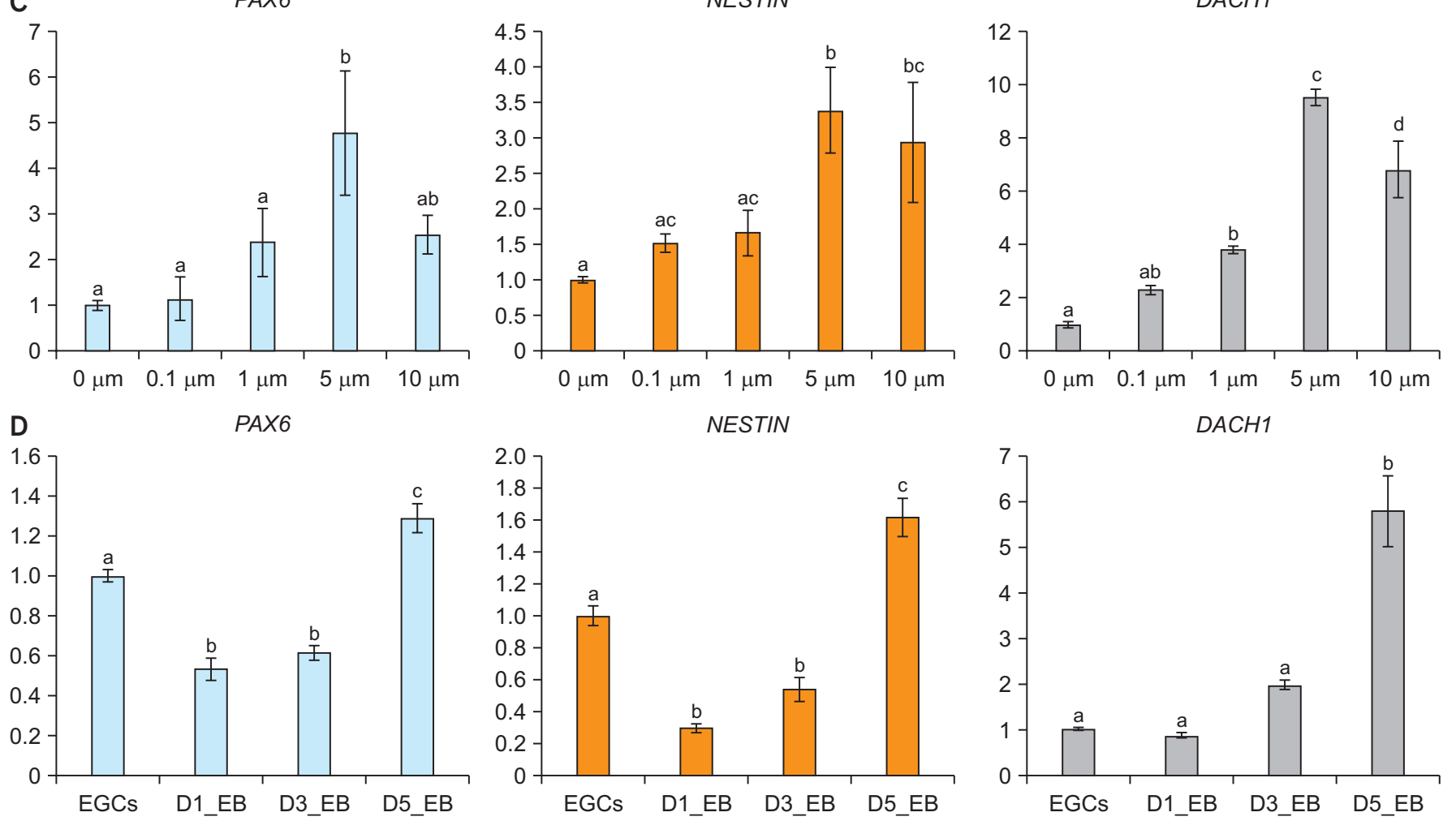

DACH1

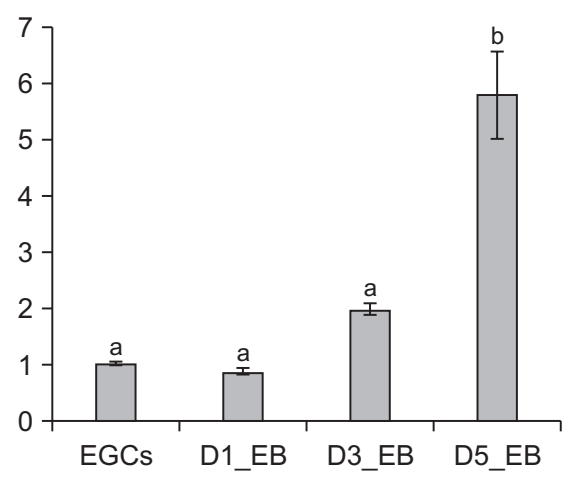

Fig. 2. Effects of RA concentration on neural differentiation in pig EGCs. (A, B) To optimize culture conditions, embryoid bodies were formed with various RA concentrations and then cultured on Matrigel for 8 days. (C) When examined with various concentrations of retinoic acid, the expression of neural markers was most efficiently up-regulated in $5 \mu \mathrm{M}$-treated groups. (D) Five $\mu \mathrm{M}$ retinoic acidinduced neural lineage-related genes during suspension culture. Scale bar $=400 \mu \mathrm{m}$.

\section{DISCUSSION}

Human pluripotent stem cell-derived neural cells such as dopaminergic neuron and retinal cells have been anticipated as alternative cell sources for cell therapy instead of fetal tissues (Osakada et al., 2008). Induction of neuronal lineages from pluripotent cells has been accomplished by co-culture with feeder cells made of PA6 stromal cells or culture with serum-free media containing signaling molecules including retinoic acid and inhibitors of SMAD signaling (reviewed in (Schwartz et al., 2008)). Depending on the combination of signaling molecules, pluripotent stem cells (PSCs) have been able to differentiate into various types of neurons including dopaminergic neurons (Lee 

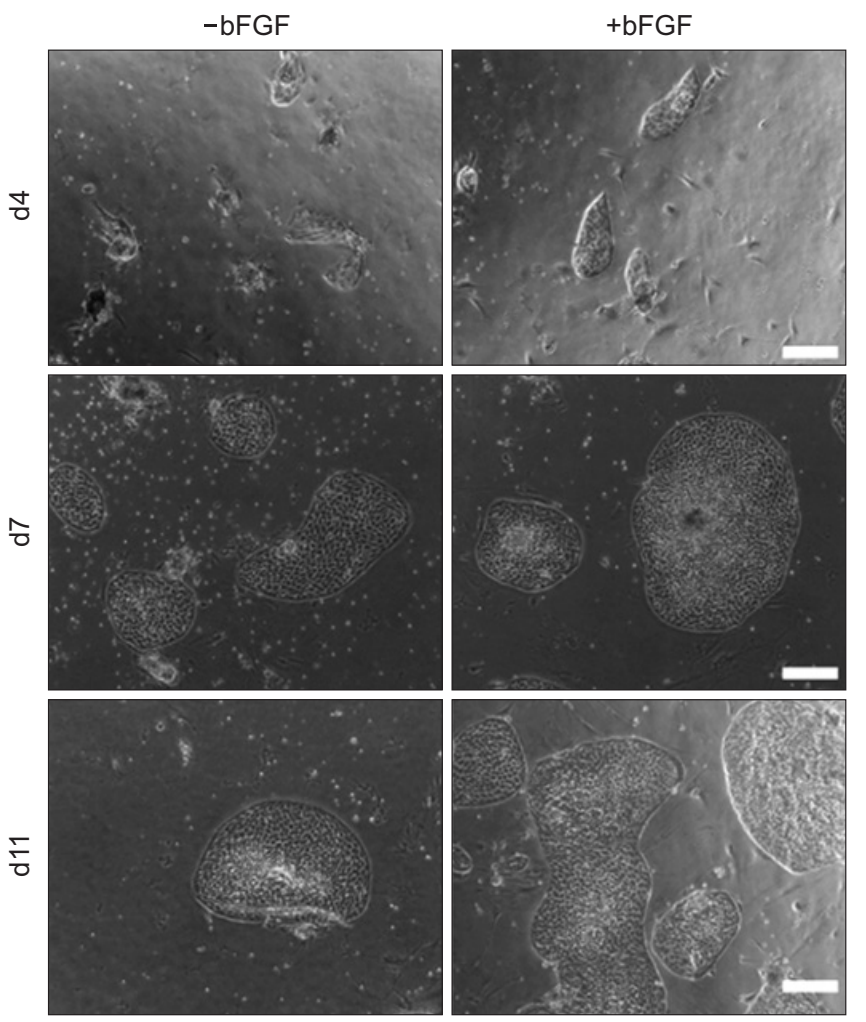

Fig. 3. Effects of bFGF on the growth of neural progenitor cells. Basic FGF treatment during adherent culture facilitated the proliferation of neural progenitor cells. Scale bar $=400 \mu \mathrm{m}$.

et al., 2000), motor neurons (Wichterle et al., 2002), cerebral cortex (Eiraku et al., 2008) and pituitary (Suga et al., 2011) and cortical pyramidal neurons (Espuny-Camacho et al., 2013). Interestingly, neuroectodermal cells derived from PSCs could recapitulate in vivo-development and form multicellular organs, called brain organoid, through three-dimensional culture with extracellular matrix (Matrigel) (Lancaster et al., 2013). Because they more closely resemble in vivo-organs and tissues than a single type of cells, brain organoids might provide in vitro-tools for drug screening, disease modeling and organ development models (Yin et al., 2016).

Studies on stem cells of large animals have been proven important for preclinical researches of human disease. So, many researchers have been attempted to convert the porcine stem cells into neuronal lineages and transplant the differentiated cells into the pigs (Puy et al., 2010; Zhou et al., 2011; Gallegos-Cardenas et al., 2015). First of all, neuronal differentiation has successfully induced from in vitro-cultured ICM and iPSCs. During in vitro-culture, pig ICMs were spontaneously differentiated

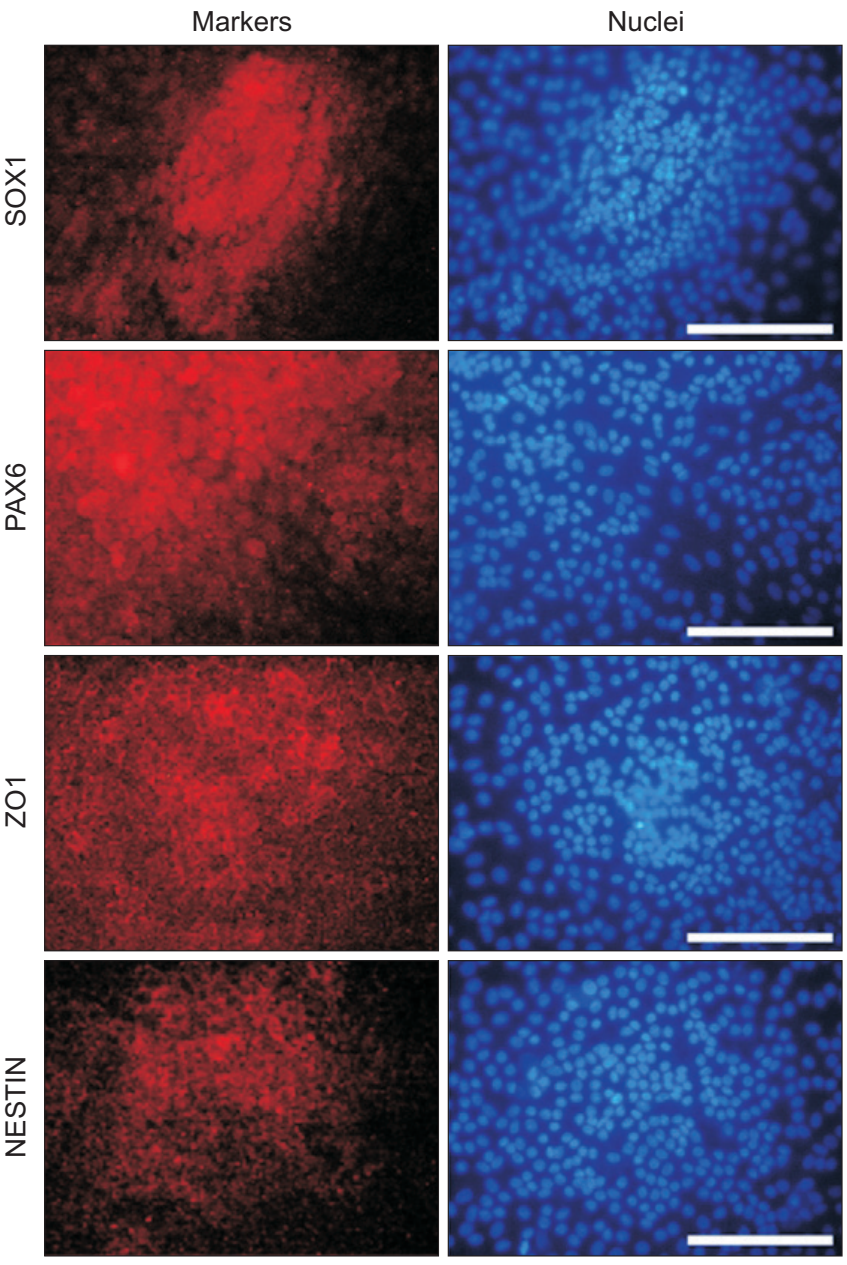

Fig. 4. Expression of neural markers as determined by immunostaining. The expression of neural markers such as SOX1, PAX6, ZO1, and NESTIN was determined by immunostaining. Scale bar $=200 \mu \mathrm{m}$.

into neural rosette-like structures while they couldn't be maintained during an expanded culture (Puy et al., 2010). The cells isolated from neural rosette-like structures could be developed into neurons including astrocyte and oligodendrocytes. In another study, researchers successfully induced neural progenitor cells from pig iPSCs (GallegosCardenas et al., 2015). It was assessed that neural differentiation of pig iPSCs resembles that of human PSCs in terms of gene expression pattern, which means pig PSCs could provide valid models for human therapy. In addition, Zhou and colleagues tried to transplant differentiated cells into pig disease models. Rod photoreceptors were produced from pig iPSCs, and then these cells were engrafted into the subretinal space of pigs (Zhou et al., 2011). The transplanted cells have successfully resided in 
the subretinal region.

In this study, we attempted to derive neuronal progenitor cells from pig EGCs according to the serum-free floating culture of the EB-aggregates (SFEB) method (Watanabe et al., 2005). Similar to other species, neuronal progenitor cells were successfully induced by treatment of retinoic acid and these cells expressed neuronal markers such as PAX6, NESTIN, and SOX1. In the case of the inhibition of SMAD signaling, because SMAD signaling was not sufficiently activated to interfere with the neural differentiation in pEGCs, it seems that the inhibitions have no significant effects on the neural differentiation. Despite the lack of in vivo developmental competence (Choi et al., 2018), these data indicated that specific types of somatic cells could be directly induced from pig EGCs by manipulating culture conditions. In consistent with human and mouse, the same signaling molecules were involved in neural differentiation of pig EGCs, which means pig EGCs could be applied for human researches. Recently, authentic pig ESCs having teratoma-forming capacity were derived and could directly differentiate into neural cells, pancreatic progenitors, and cardiac muscles using the culture conditions previously applied in human PSC researches, which suggests that pig model is suitable for preclinical research of human PSCs (Choi et al., 2019). To date, several transgenic pigs harboring neurological diseases such as Alzheimer's disease and spinal muscular atrophy induced by genetic modifications have been reported (Kragh et al., 2009; Lorson et al., 2011). If the development of transplantation methods into these diseasemodel animals were achieved apposing with the study on differentiation from PSCs, it would lead to the success of human cell therapy using stem cells.

\section{CONCLUSION}

Based on our results, neuronal progenitor cells could be derived directly from pig EGCs through the SFEB method. Treating retinoic acid was more efficient for inducing neuronal lineages from EGCs than inhibiting SMAD signaling. Although neuronal markers such as PAX6, NESTIN, and SOX1 were expressed, it would be more developed to maturate neurons such as astrocytes, dendrocytes and dopaminergic neurons, along with the functional test. Finally, the production of transgenic pig for disease models as well as differentiation methods will provide basic pre- clinical data for human regenerative medicine and lead to the success of stem cell therapy.

\section{CONFLICTS OF INTEREST}

No potential conflict of interest relevant to this article was reported.

\section{ACKNOWLEDGEMENTS}

This work was supported by the BK21 Plus Program and the National Research Foundation of Korea (NRF) grant funded by the Korea government (NRF2019R1C1C1004514).

\section{AUTHOR CONTRIBUTIONS}

Conceptualization: Choi KH, Lee CK. Data curation: Choi KH. Formal analysis: Choi KH, Oh JN. Funding acquisition: Choi KH, Lee CK. Investigation: Choi KH, Lee DK, Lee M, Jeong J, Choe GC. Methodology: Choi KH, Lee DK. Project administration: Choi KH, Lee CK. Resources: Lee CK. Validation: Choi KH, Kim SH. Visualization: Choi KH, Lee DK. Writing - original draft: Choi KH, Lee CK. Writing - review \& editing: Choi KH, Lee CK.

\section{AUTHOR'S POSITION AND ORCID NO.}

KH Choi, PhD,

https://orcid.org/0000-0003-3919-7413

DK Lee, PhD, https://orcid.org/0000-0003-4112-3405

JN Oh, PhD Candidate, https://orcid.org/0000-0001-9026-3725

SH Kim, PhD Candidate, https://orcid.org/0000-0002-5379-5041

M Lee, PhD Candidate, https://orcid.org/0000-0002-1853-7362

J Jeong, MS Candidate, https://orcid.org/0000-0001-9312-4384

GC Choe, MS Candidate, https://orcid.org/0000-0002-6289-5570

CK Lee, Professor, https://orcid.org/0000-0001-6341-0013 


\section{REFERENCES}

Ao Y, Mich-Basso JD, Lin B, Yang L. 2014. High efficient differentiation of functional hepatocytes from porcine induced pluripotent stem cells. PLoS One 9:e100417.

Choi KH and Lee CK. 2019. Pig pluripotent stem cells as a candidate for biomedical application. J. Anim. Reprod. Biotechnol. 34:139-147.

Choi KH, Lee DK, Kim SW, Woo SH, Kim DY, Lee CK. 2019. Chemically defined media can maintain pig pluripotency network in vitro. Stem Cell Reports 13:221-234.

Choi KH, Lee DK, Oh JN, Son HY, Lee CK. 2018. FGF2 signaling plays an important role in maintaining pluripotent state of pig embryonic germ cells. Cell. Reprogram. 20:301-311.

Eiraku M, Watanabe K, Matsuo-Takasaki M, Kawada M, Yonemura S, Matsumura M, Wataya T, Nishiyama A, Muguruma K, Sasai Y. 2008. Self-organized formation of polarized cortical tissues from ESCs and its active manipulation by extrinsic signals. Cell Stem Cell 3:519-532.

Espuny-Camacho I, Michelsen KA, Gall D, Linaro D, Hasche A, Bonnefont J, Bali C, Orduz D, Bilheu A, Herpoel A, Lambert N, Gaspard N, Péron S, Schiffmann SN, Giugliano M, Gaillard A, Vanderhaeghen P. 2013. Pyramidal neurons derived from human pluripotent stem cells integrate efficiently into mouse brain circuits in vivo. Neuron 77:440-456.

Gallegos-Cárdenas A, Webb R, Jordan E, West R, West FD, Yang JY, Wang K, Stice SL. 2015. Pig induced pluripotent stem cell-derived neural rosettes developmentally mimic human pluripotent stem cell neural differentiation. Stem Cells Dev. 24:1901-1911.

Genovese NJ, Domeier TL, Telugu BP, Roberts RM. 2017. Enhanced development of skeletal myotubes from porcine induced pluripotent stem cells. Sci. Rep. 7:41833.

Kragh PM, Nielsen AL, Li J, Du Y, Lin L, Schmidt M, Bøgh IB, Holm IE, Jakobsen JE, Johansen MG, Purup S, Bolund L, Vajta G, Jørgensen AL. 2009. Hemizygous minipigs produced by random gene insertion and handmade cloning express the Alzheimer's disease-causing dominant mutation APPsw. Transgenic Res. 18:545-558.

Lancaster MA, Renner M, Martin CA, Wenzel D, Bicknell LS, Hurles ME, Homfray T, Penninger JM, Jackson AP, Knoblich JA. 2013. Cerebral organoids model human brain development and microcephaly. Nature 501:373-379.

Lee AS, Tang C, Rao MS, Weissman IL, Wu JC. 2013. Tumorigenicity as a clinical hurdle for pluripotent stem cell therapies. Nat. Med. 19:998-1004.

Lee SH, Lumelsky N, Studer L, Auerbach JM, McKay RD. 2000. Efficient generation of midbrain and hindbrain neurons from mouse embryonic stem cells. Nat. Biotechnol. 18:675-679.

Li X, Zhang F, Song G, Gu W, Chen M, Yang B, Li D, Wang D, Cao K. 2013. Intramyocardial injection of pig pluripotent stem cells improves left ventricular function and perfusion: a study in a porcine model of acute myocardial infarction. PLoS One 8:e66688.

Livak KJ and Schmittgen TD. 2001. Analysis of relative gene expression data using real-time quantitative PCR and the 2(-Delta Delta C(T)) method. Methods 25:402-408.

Lorson MA, Spate LD, Samuel MS, Murphy CN, Lorson CL, Prather RS, Wells KD. 2011. Disruption of the Survival Motor Neuron (SMN) gene in pigs using ssDNA. Transgenic. Res. 20:1293-1304.

Osakada F, Sasai Y, Takahashi M. 2008. Control of neural differentiation from pluripotent stem cells. Inflamm. Regen. 28:166-173.

Park KM, Hussein KH, Ghim JH, Ahn C, Cha SH, Lee GS, Hong SH, Yang S, Woo HM. 2015. Hepatic differentiation of porcine embryonic stem cells for translational research of hepatocyte transplantation. Transplant. Proc. 47:775-779.

Parsons XH, Teng YD, Parsons JF, Snyder EY, Smotrich DB, Moore DA. 2011. Efficient derivation of human neuronal progenitors and neurons from pluripotent human embryonic stem cells with small molecule induction. J. Vis. Exp. (56):e3273.

Puy Ld, Chuva de Sousa Lopes SM, Haagsman HP, Roelen BA. 2010. Differentiation of porcine inner cell mass cells into proliferating neural cells. Stem Cells Dev. 19:61-70.

Schwartz PH, Brick DJ, Stover AE, Loring JF, Müller FJ. 2008. Differentiation of neural lineage cells from human pluripotent stem cells. Methods 45:142-158.

Sohn EH, Jiao C, Kaalberg E, Cranston C, Mullins RF, Stone EM, Tucker BA. 2015. Allogenic iPSC-derived RPE cell transplants induce immune response in pigs: a pilot study. Sci. Rep. 5:11791.

Suga H, Kadoshima T, Minaguchi M, Ohgushi M, Soen M, Nakano T, Takata N, Wataya T, Muguruma K, Miyoshi H, Yonemura S, Oiso Y, Sasai Y. 2011. Self-formation of functional adenohypophysis in three-dimensional culture. Nature 480:57-62.

Tabar V and Studer L. 2014. Pluripotent stem cells in regenerative medicine: challenges and recent progress. Nat. Rev. Genet. 15:82-92.

Wang H, Xiang J, Zhang W, Li J, Wei Q, Zhong L, Ouyang H, Han J. 2016. Induction of germ cell-like cells from porcine induced pluripotent stem cells. Sci. Rep. 6:27256.

Watanabe K, Kamiya D, Nishiyama A, Katayama T, Nozaki S, Kawasaki H, Watanabe Y, Mizuseki K, Sasai Y. 2005. Directed differentiation of telencephalic precursors from embryonic stem cells. Nat. Neurosci. 8:288-296.

Wichterle H, Lieberam I, Porter JA, Jessell TM. 2002. Directed differentiation of embryonic stem cells into motor neurons. Cell 110:385-397.

Yin X, Mead BE, Safaee H, Langer R, Karp JM, Levy O. 2016. Engineering stem cell organoids. Cell Stem Cell 18:25-38.

Zhang F, Song G, Li X, Gu W, Shen Y, Chen M, Yang B, Qian L, Cao K. 2014. Transplantation of iPSc ameliorates neural remodeling and reduces ventricular arrhythmias in a postinfarcted swine model. J. Cell. Biochem. 115:531-539.

Zhou L, Wang W, Liu Y, Fernandez de Castro J, Ezashi T, Telugu BP, Roberts RM, Kaplan HJ, Dean DC. 2011. Differentiation of induced pluripotent stem cells of swine into rod photoreceptors and their integration into the retina. Stem Cells 29:972-980. 